\title{
THE BRITISH JOURNAL OF NUTRITION
}

VOL. 9, NO. 2

1955

PRICE 30s.net

EDITED FOR THE NUTRITION SOCIETY

Editorial Board
A. L. BACHARACH
L. J. HARRIS
S. J. COWELL
E. M. HUME
D. P. CUTHBERTSON
A. P. MEIKLEJOHN
J. N. DAVIDSON
A. T. PHILLIPSON
R. C. GARRY
J. A. B. SMITH
J. HAMMOND
F. YATES

S. K. KON (Chairman)

CAMBRIDGE UNIVERSITY PRESS

LONDON: BENTLEY HOUSE, N.W.1

NEW YORK: 32 EAST 57TH STREET, 22 
The Nutrition Society has as its object the advancement of the scientific study of nutrition and its application to the maintenance of human and animal health.

Membership is open to any whose work has contributed to the scientific knowledge of nutrition, whether such work has been in the laboratory, the field or the clinic, and whether experimental, clinical, agricultural or statistical in nature.

Particulars of The Nutrition Society and application forms for membership may be had from the Honorary Secretary, DR G. H. Bourne, Histology Department, London Hospital Medical College, Turner Street, London, E. I.

The Proceedings of The Nutrition Society, published by the Cambridge University Press, in part record meetings of the Symposium type, at which experts in a particular field are invited by Council to make contributions on specific parts thereof and at which general discussion follows these invited contributions. The contributions will be published in extenso; such summaries of the ensuing discussions as circumstances warrant may also be published. The Society also holds scientific meetings at which papers are communicated by members and others on original work carried out by them. It is proposed at present to publish summaries of these papers, of which about ten may be read at each meeting, each communication being recorded in the Society's Proceedings by means of an abstract not exceeding in length 400 words or the equivalent space in print. The Proceedings will be published twice a year.

The British Journal of Nutrition is published by the Cambridge University Press for The Nutrition Society, which owns it and controls its publication. It is devoted to reports of original work in all branches of nutrition. A volume will consist of four parts and one volume will appear each year.

Subscriptions to the Society's Publications. For non-members of The Nutrition Society the combined subscription to the fournal and the Proceedings, including postage, is $£^{6}$ per annum, payable in advance to the Cambridge University Press, Bentley House, 200 Euston Road, London, N.W. I, or to any bookseller. The combined subscription in U.S.A. is $\$ 20.00$, and inquiries should be addressed to the Cambridge University Press, American Branch, at 32 East 57 th Street, New York 22.

The price for single issues of the fournal or of the Proceedings is 3 os. (U.S.A. $\$ 5.00)$, postage extra.

A claim for the replacement of a publication lost in transmission will not be entertained if it is received more than 3 months after the date of posting.

Back Numbers of the Proceedings, $1940-7$ (Volumes $x-5$ ). Complete sets of these volumes, and a few separate numbers, are still available. For particulars see advertisements, p. v. 